\title{
Characterizing avian survival along a rural-to-urban land use gradient
}

\author{
Brian S. Evans, ${ }^{1,2,4}$ Thomas B. Ryder, ${ }^{2}$ Robert Reitsma, ${ }^{2}$ Allen H. Hurlbert, ${ }^{1,3}$ and Peter P. Marra ${ }^{2}$ \\ ${ }^{1}$ Curriculum for the Environment and Ecology, University of North Carolina, Chapel Hill, North Carolina 27599 USA \\ ${ }^{2}$ Migratory Bird Center, Smithsonian Conservation Biology Institute, National Zoological Park, P.O. Box 37012-MRC 5503, \\ Washington, D.C. 20013 USA \\ ${ }^{3}$ Department of Biology, University of North Carolina, Chapel Hill, North Carolina 27599 USA
}

\begin{abstract}
Many avian species persist in human-dominated landscapes; however, little is known about the demographic consequences of urbanization in these populations. Given that urban habitats introduce novel benefits (e.g., anthropogenic resources) and pressures (e.g., mortality risks), conflicting mechanisms have been hypothesized to drive the dynamics of urban bird populations. Top-down processes such as predation predict reduced survivorship in suburban and urban habitats, whereas bottom-up processes, such as increased resource availability, predict peak survival in suburban habitats. In this study, we use mark-recapture data of seven focal species encountered between 2000 and 2012 to test hypotheses about the processes that regulate avian survival along an urbanization gradient in greater Washington, D.C., USA. American Robin, Gray Catbird, Northern Cardinal, and Song Sparrow exhibited peak survival at intermediate and upper portions of the rural-to-urban gradient; this pattern supports the hypothesis that bottom-up processes (e.g., resource availability) can drive patterns of avian survival in some species. In contrast, Carolina Chickadee showed no response and Carolina and House Wren showed a slightly negative response to urban land cover. These contrasting results underscore the need for comparative studies documenting the mechanisms that drive demography and how those factors differentially affect urban adapted and urban avoiding species.
\end{abstract}

Key words: avian demography; birds; citizen science; land use gradients; mark-recapture; Neighborhood Nestwatch; resource availability; survival; top-down vs. bottom-up processes; urbanization; Washington, D.C., USA.

\section{INTRODUCTION}

Urbanization has altered habitats, restructured avian communities, and influenced the abundance and distribution of bird populations (McKinney and Lockwood 1999, Marzluff et al. 2001, Chace and Walsh 2006). The unique characteristics of human-built environments confer a conflicting set of benefits and challenges that make it difficult to determine whether urban habitats are advantageous or constitute demographic sinks (Gates and Gysel 1978) for bird populations. As the developed land area in the United States is projected to nearly double between 2000 and 2025 (Alig et al. 2004), understanding how organisms respond to these habitats is of paramount importance. Despite the urgency of the problem for conservation, however, the population-level consequences of urbanization on birds remain poorly understood (Shochat et al. 2006).

It is hypothesized that changes in the distribution of resources in anthropogenic habitats may impart bottomup controls on urban bird populations (Shochat et al.

Manuscript received 30 January 2014; revised 18 September 2014; accepted 7 October 2014; final version received 10 November 2014. Corresponding Editor: J. R. Sauer.

${ }^{4}$ E-mail: bsevans.unc@gmail.com
2010). Human-dominated environments often contain an abundance of consistent food resources for many species of birds. For example, supplemental feeding by humans, especially for overwintering resident birds, has been found to be positively associated with adult survivorship for a number of granivorous birds (Doherty and Grubb 2002). Likewise, human-dominated landscapes are also often dominated by ornamental and invasive species, which have been found to provide essential resources for frugivorous bird species, especially during winter months (e.g., Leston and Rodewald 2006, McCusker et al. 2010). The low temporal variability of resources in anthropogenic habitats is also hypothesized to support higher densities of individuals because they can persist in a state of reduced body condition relative to their rural counterparts (Shochat 2004). Viewed cumulatively, the abundance and quality of avian food resources is expected to vary spatially along the rural-to-urban gradient with resource subsidization as the primary driver of higher food availability at intermediate degrees of urbanization (Raupp et al. 2010).

The benefits of anthropogenic resources, however, may be offset by costs associated with the quality of resources available. For instance, plant communities 
dominated by nonnative species may support lower concentrations of protein-rich arthropod resources (Tallamy 2004), which are necessary for nestling and fledgling development (Atchison and Rodewald 2006, Chamberlain et al. 2009). This may lead to lower nestling survivorship, poorer fledging quality, and structurally smaller adults (Liker et al. 2008). Therefore, although the temporal and spatial distribution of resources may allow some bird species to maintain high densities in urban habitats, it also may result in fitness trade-offs and differential selection for specific life history stages and traits (Shochat 2004).

The resource advantages of urbanization for some species may also be offset by top-down controls imparted by unique hazards associated with urban environments. For example, birds may experience higher rates of predation in urban environments due to high densities of small- and medium-sized mammalian predators (Crooks and Soulé 1999), novel humansubsidized predators (e.g., free-roaming cats, Balogh et al. 2011, Loss et al. 2013), and locally high densities of raptors and corvids (Chace and Walsh 2006). Collisions with manmade objects, such as buildings and automobiles, are another threat expected to be a considerable source of mortality for urban birds (Chace and Walsh 2006, Loss et al. 2014a, b). Urban bird populations are also exposed to higher levels of pollutants, such as lead (Roux and Marra 2007), that could negatively affect vital rates. Finally, rates of disease transmission are also higher in urban areas (Kilpatrick 2011), with the effects potentially exacerbated by increased avian densities around common resources such as bird feeders (Robb et al. 2008).

Despite evidence that urban environments can present opposing selection pressures, our understanding of the processes and mechanisms that regulate species persisting in urban landscapes are poorly understood. Research to date on certain life history stages, e.g., postfledging survival (Whittaker and Marzluff 2009, Ausprey and Rodewald 2011) and nestling survival (Ryder et al. 2010), have failed to document a negative impact of urbanization. Despite its importance for population demography, adult survival is rarely estimated along the rural-to-urban land use gradient. To date, most studies on the impacts of urbanization on adult survivorship have compared rural and urban populations (e.g., Horak and Lebreton 1998) or have examined forested patches embedded within the broader matrix (e.g., Rodewald and Shustack 2008b). These studies have found little or no effect of urbanization on adult survivorship. No studies have yet been conducted on avian adult survival across the continuous rural-tourban land use gradient from within the urban and suburban matrix where many populations achieve peak densities (Blair 1996, Ryder et al. 2010).

Here we use mark-recapture and resight data to test two mutually exclusive hypotheses about the processes that regulate annual adult survivorship of seven urban- adapted bird species. Given conflicting top-down and bottom-up processes in urban environments, variation in ecological pressures across the urbanization gradient can produce differential patterns of avian survival. If top-down processes such as disease, collision, or pollution are the primary drivers of variation in survival, we predict reduced survival in urban environments. Likewise, if predation drives patterns of survival we predict lower survival in suburban habitats, where domestic cats achieve their highest densities (Balogh et al. 2011). In contrast, if bottom-up processes drive variation in survival, we expect survivorship to show a quadratic relationship with peak survival at intermediate degrees of urbanization (increased food resources) and reduced survival in core urban and rural habitats. To test these hypotheses, we develop and compare a set of competing models of annual survivorship using various combinations of model covariates.

\section{Methods}

This study was conducted from 2000 to 2012 within a $100-\mathrm{km}$ spatial extent encompassing a rural-to-urban land use gradient in the greater Washington, D.C., USA, metropolitan region. Research in urban environments is often limited by accessibility and adequate coverage of the urban gradient (Cooper et al. 2007). To alleviate this problem, we utilized sites that were part of Neighborhood Nestwatch (hereafter referred to as "NN"), an ongoing citizen science project run by the Smithsonian Migratory Bird Center. NN is a network of banding stations $(n=242)$ located at private residences, community centers, and schools, as well as within forested and agricultural locations (Fig. 1). By incorporating privately owned land within our study design, we were able to capture portions of the urban and suburban matrix not normally monitored in avian survivorship studies. To assess whether NN sites adequately represent the urbanization gradient within our study area, we compared the proportional land cover within a $500 \mathrm{~m}$ radius of sampled sites to randomly selected sites within our study region using a two-sample KolmogorovSmirnov test. These analyses showed that our sampled sites were largely representative of the distribution of land cover types typically used to characterize the ruralto-urban gradient (e.g., core urban, suburban, agricultural, and forested; Appendix A: Table A1, Fig. A1).

Annually, NN technicians visit participant properties during the avian breeding season (between the months of May and August, sites are predominantly visited by one technician). During each visit, technicians provide an educational banding demonstration with 2-8 mist nets for a period of 3-5 hours of mark-recapture. Birds are captured using target netting with playback of mobbing calls or conspecific song. Individuals are marked with a unique U.S. Fish and Wildlife Service aluminum band and a unique combination of colored plastic bands. Technicians measure body mass (to the nearest $0.01 \mathrm{~g}$ ) on an electronic balance and unflattened 


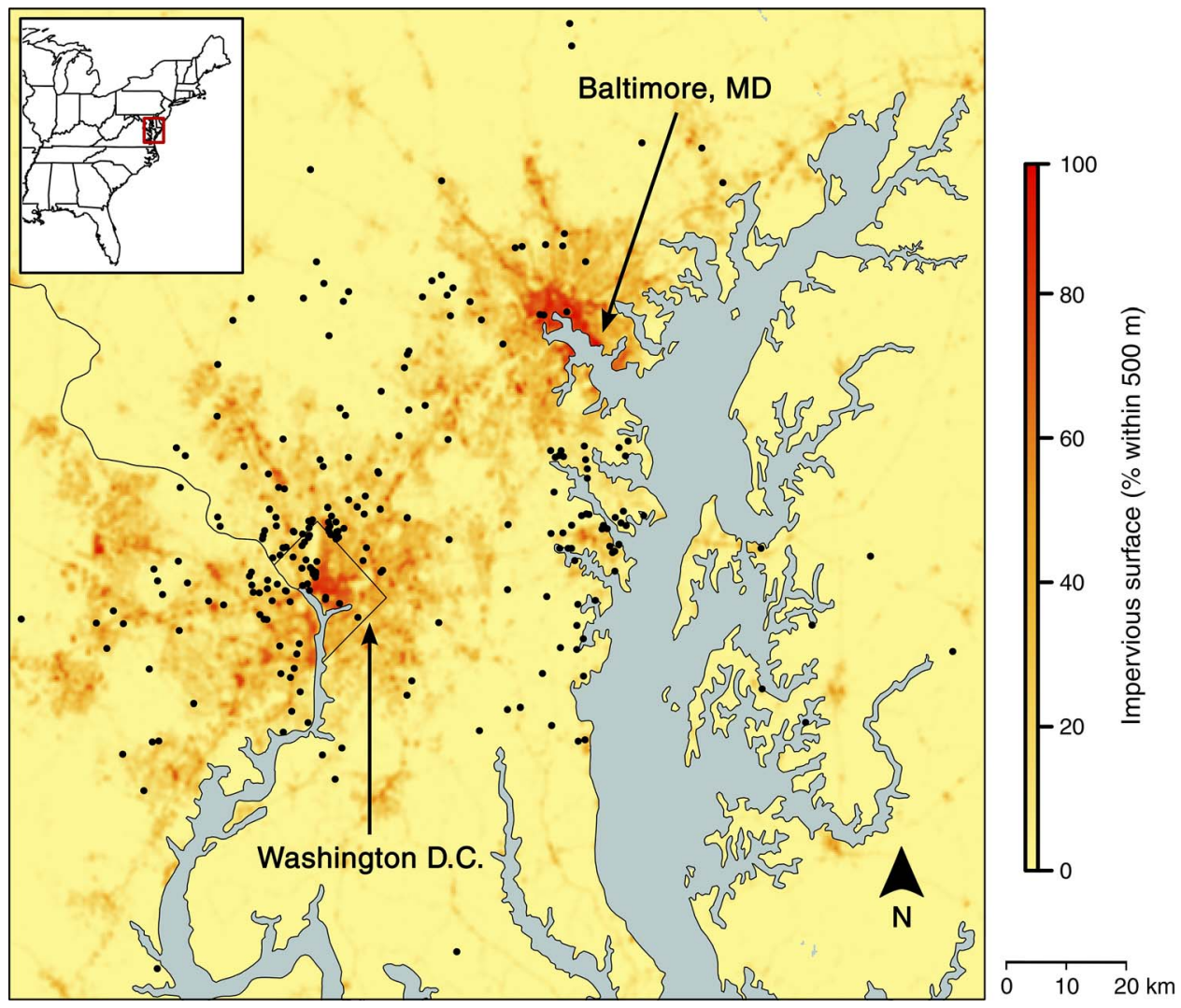

FIG. 1. The urbanization gradient as characterized by impervious surface and sampling sites $(n=242)$ of the Neighborhood Nestwatch Program in greater Washington, D.C., USA, which formed the framework for the demographic analyses. The inset map displays the general study region within the continental United States.

wing chord (to the nearest $0.25 \mathrm{~mm}$ ) with a wing rule. Birds are aged into hatch year (HY) and after hatch year (AHY) age classes using plumage, skull ossification, or molt criteria (methodologies vary by species; see Pyle et al. 1997). During each banding visit, technicians spend one hour attempting to resight previously captured individuals within a $200 \mathrm{~m}$ radius of the banding station using playback techniques. Project participants are provided with a list of color-banded birds, trained on resighting techniques, and are expected to report observations of marked individuals throughout the year.

We estimated the annual survival of seven species of birds most common across the development gradient within our study region: American Robin (Turdus migratorius), Carolina Chickadee (Poecile carolinensis), Carolina Wren (Thryothorus ludovicianus), Gray Catbird (Dumetella carolinensis), House Wren (Troglodytes aedon), Northern Cardinal (Cardinalis cardinalis), and Song Sparrow (Melospiza melodia). Species showed variation in capture rates along the sampling gradient due to differences in abundance (see Appendix A: Fig. A2). We fit Cormack-Jolly-Seber survivorship models to these data to investigate the effects of individual covariates on apparent survivorship $(\Phi)$ and the probability of detecting marked individuals, given that they remained within the sampling location $(p)$. All models were constructed in the $\mathrm{R}$ package RMark v. 2.14.1 (Laake 2013, R Core Team 2014) and implemented in Program MARK (White and Burnham 1999). Covariates used in model construction were unstandardized and are described in detail (also see Table 1).

We used Akaike's information criterion, AIC (Akaike 1973), to select the best models among a set of biologically plausible candidate models. Models in which the $\Delta \mathrm{AIC}_{\mathrm{c}}$ between a given model and the best model was less than 2 were considered equally supported by the data (Burnham and Anderson 2002). We used normalized Akaike weights, the ratio of the likelihood of a given model relative to the sum of the likelihood across models, to evaluate the weight of evidence for a given model relative to the full set of candidate models. We further assessed the effects of predictor variables by averaging $\beta$ estimates and unconditional standard errors by their AIC weights across the candidate model set (Burnham and Anderson 2002).

To account for variation or potential bias in the estimates of detectability and survivorship, we constructed an a priori model for each species that included sex, time since marking, body condition, and project 
TABLE 1. Variables used in the development of a priori and urbanization models for apparent survivorship $(\Phi)$ and the probability of detecting marked individuals, given that they remained within the sampling location $(p)$.

\begin{tabular}{|c|c|c|c|}
\hline Model set & Variable & Variable description & Parameter \\
\hline a priori & BCI & scaled body condition index & $\Phi \dagger, \ddagger, \S$ \\
\hline a priori & $\operatorname{sex}$ & binary sex (male, female) & $\Phi^{\mathrm{a}, \mathrm{b}}, p \dagger, \ddagger, \S$ \\
\hline a priori & tsm & binary time since marking & $\Phi \dagger, \uparrow, \S$ \\
\hline a priori & Sex $\times$ BCI & interaction term between sex and body condition index & $\Phi \dagger+\dagger$ \\
\hline a priori & Sex $\times$ tsm & interaction term between sex and time since marking & $\Phi \dagger+$ \\
\hline a priori & part & binary active vs. inactive participation by citizen scientists & $p \dagger$ \\
\hline Urbanization & IMP & impervious surface cover $(\%)$ & $\Phi \dagger, \ddagger, \S$ \\
\hline Urbanization & $\mathrm{IMP}^{2}$ & impervious surface, quadratic form & $\Phi \dagger, \dagger, \S$ \\
\hline Urbanization & IMP $\times \operatorname{sex}$ & interaction term between impervious surface and sex & $\Phi \dagger, \dagger, \S$ \\
\hline
\end{tabular}

Note: Continuous variables are in uppercase and factors are in lowercase.

$\dagger$ For AMRO, CACH, GRCA, NOCA, the a priori model for $\Phi$ is sex $+\mathrm{BCI}+\mathrm{tsm}+\operatorname{sex} \times \mathrm{BCI}+\operatorname{sex} \times$ tsm; the a priori model for $p$ is (sex + part).

$\$$ For CARW, the a priori model for $\Phi$ is sex $+\mathrm{BCI}+\mathrm{tsm}+\operatorname{sex} \times \mathrm{BCI}+\operatorname{sex} \times \operatorname{tsm}$; that for $p$ is sex.

$\S$ For SOSP and HOWR, the a priori model for $\Phi$ is BCI + tsm; that for $p$ is sex + part.

participant resight effort covariates. Because model selection and subsequent parameter estimates can become unstable (high variance) by over-fitting models ( $>10$ parameters), especially when there is an insufficient sample size for an individual group variable (Breiman 1996, Burnham and Anderson 2002), we constrained our model set to those in which the parameter estimates were identifiable. Here we are referring to extrinsic identifiability, where parameter estimates are at or near their boundary ( 0 or 1$)$ or are otherwise unidentifiable because of insufficient sample size. Ultimately, we excluded these "over-parameterized" models that contained more parameters than can be accommodated by the data (J. L. Laake, personal communication). Therefore not all covariates could be included in a priori models for each species (see Table 1).

Territorial males may be much more likely to be encountered than females due to behavioral differences (Amrhein et al. 2012); therefore sex was included as a binary dummy covariate for estimating detectability. Likewise, because males and females may experience differential rates of survival (Donald 2007) or site fidelity (Murphy 1996), sex was also used as a covariate for $\Phi$ to account for variation in survival or emigration.

A population of birds captured during a given sampling event could contain both transient and resident individuals. Because there is a low probability of reencountering transient birds, failure to account for this could negatively bias survival estimates (Pradel 1996). We incorporated transience in the model structure by including a binary time-since-marking (tsm) term for the estimation of $\Phi$. We then calculated separate survival estimates for the year after the initial capture occasion and between the second and following years of sampling. Because males and females may show differential rates of transience (Murphy 1996), an interaction term between tsm and sex was included within the a priori model.

Body condition is a potentially important determinant of avian survivorship in different environments (Johnson et al. 2006) and is theorized to decline in urban environments (Shochat 2004). To incorporate the effects of body condition on $\Phi$, we used a scaled body condition index (BCI) derived from body mass and wing chord lengths (Peig and Green 2009). Because variation in body condition may have differential effects on the survival of males and females, we included an interaction term between sex and BCI within the a priori model.

Although we acknowledge the potential of time dependence in both survivorship and detection probabilities, models with both time and covariates had insufficient sample size to provide identifiable parameters. However, to examine the potential for temporal variation in vital rates, we ran simplified models in which survival was a function of time for all seven species. Of the seven species, only Carolina Wren showed significant differences in survival among years $\left(\chi^{2}=37.11, \mathrm{df}=10, P=0.0001\right)$. A reduced model set for Carolina Wren with an impervious surface $\times$ year interaction received some support, but was not the best-supported model (Appendix B: Table B1). Due to funding and logistical constraints, neither resighting nor banding effort was consistent across years and several sites were not sampled during every year of the study or were discontinued. To account for this, individual observations in the encounter history were coded as encounter occasions, occasions in which an individual was not encountered, and unsampled occasions ("1", " 0 ", and ".", respectively). Although this technique is used to account for missing sampling data (e.g., Danner et al. 2013), a drawback of this method is that goodnessof-fit tests are not currently available to estimate overdispersion with missing data.

We examined the influence of citizen scientist sampling in our study by comparing estimates of detectability using data gathered by citizen scientists vs. those collected by NN technicians. Because both technicians and participants attempted to resight birds at several locations, we were unable to evaluate the origin of individual observations. To account for citizen scientist participation, we therefore separated encounter records 
TABLE 2. Counts of captured and re-encountered birds in the Neighborhood Nestwatch program across years.

\begin{tabular}{|c|c|c|c|c|c|c|c|}
\hline \multirow[b]{2}{*}{ Species } & \multirow[b]{2}{*}{ Code } & \multicolumn{3}{|c|}{ Captures } & \multicolumn{3}{|c|}{ Recaptures } \\
\hline & & Female & Male & Total & Female & Male & Total \\
\hline American Robin & AMRO & 198 & 218 & 416 & 24 & 22 & 46 \\
\hline Carolina Chickadee & $\mathrm{CACH}$ & 192 & 211 & 403 & 43 & 57 & 100 \\
\hline Carolina Wren & CARW & 211 & 251 & 462 & 37 & 74 & 111 \\
\hline Gray Catbird & GRCA & 329 & 646 & 975 & 38 & 143 & 181 \\
\hline House Wren & HOWR & 191 & 432 & 623 & 15 & 49 & 64 \\
\hline Northern Cardinal & NOCA & 402 & 603 & 1005 & 85 & 186 & 271 \\
\hline Song Sparrow & SOSP & 101 & 407 & 508 & 21 & 131 & 152 \\
\hline Total across spp. & & 1624 & 2768 & 4392 & 263 & 662 & 925 \\
\hline
\end{tabular}

into those that originated from sites that included participant data ("active" sites, $n=100$ ) and those that did not ("inactive" sites, $n=140$ ), coded as a binary dummy variable.

To assess the effect of urbanization on avian survival, we compared the a priori model for each species with models that included our urbanization metric, impervious surface (Table 1). To characterize the degree of urbanization at each banding location, we used the raster package in $\mathrm{R}$ (Hijmans 2014) to calculate the proportion of impervious surface $(30 \mathrm{~m}$ resolution, Fry et al. 2011) within a 500-m neighborhood of each sampling location. Because avian response to urbanization is probably nonlinear, we included both linear (IMP) and quadratic (IMP ${ }^{2}$ ) impervious terms as model covariates. This proxy variable and scale of analysis have been found to be most predictive of avian demographic response to urbanization (see Ryder et al. 2010) and have been found to adequately reflect the variation in habitat distribution and quality across the rural-to-urban gradient (reviewed in McKinney 2002). Across our samples, impervious surface was highly predictive of core urban and suburban land cover types, with sites at the rural end of the urbanization gradient predominantly composed of agricultural or forested habitats (see Appendix A: Fig. A3).

\section{RESULTS}

In total, 4379 individuals were used in this analysis (Fig. 1, Table 2). Among these individuals, 79\% were never reencountered $(n=3462)$. Across species, the $\Delta \mathrm{AIC}_{\mathrm{c}}$ of the full a priori model relative to a null model with no covariates $(\Phi \sim 1, p \sim 1)$ was 18.5 , suggesting considerable support for the inclusion of a priori variables. Detailed results on the impact of citizen scientist participation on detection probability are presented in Appendix B: Table B2, Fig. B1. There was supportive evidence that survival and detection estimates varied markedly between males and females and by species (reported across time-since-marking classes in Fig. 2). Sex-specific estimates of survival and detection were not identifiable for House Wren or Song Sparrow because of small sample sizes (see Fig. 2).

Models that included additional urbanization variables received some support for six of the seven species
(Table 3). There was strong model support for variation in annual survivorship along the rural-to-urban gradient for American Robin, Song Sparrow, Northern Cardinal, and Gray Catbird (Fig. 3, Table 4). Annual survival probabilities for American Robin and Song Sparrow were highest at intermediate levels of urbanization $(45 \%$ and $47 \%$ impervious surface, respectively), with both species exhibiting a strong quadratic response to impervious surface (Fig. 3, Table 4). Northern Cardinal and Gray Catbird exhibited a nearly linear increase in apparent survival with increasing urbanization. Although there was substantial support for models that included a quadratic response to impervious surface cover for both of these species, estimates at the upper end of the rural-to-urban gradient contained considerable uncertainty due to small sample sizes at highly urban sites (see Appendix A: Fig. A2). In contrast, the a priori model and impervious surface models received equal support for Carolina and House Wren, with apparent annual survival decreasing with urbanization (Fig. 3, Table 4). However, no individuals of these
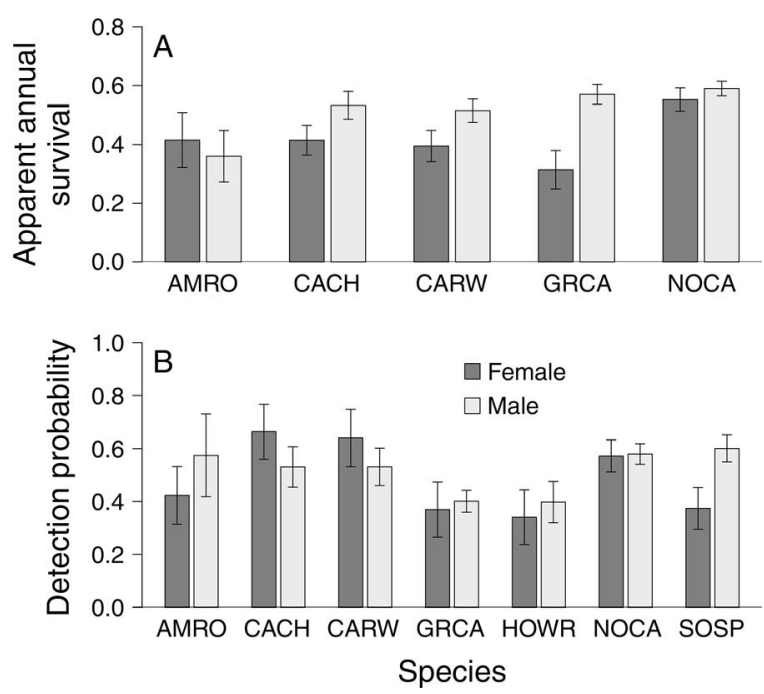

FIG. 2. Estimates (mean $\pm \mathrm{SE}$ ) of (A) annual survival and (B) detection by species and sex along an urbanization gradient in greater Washington, D.C., USA. See Table 2 for species names by code. House Wren and Song Sparrow did not have sufficient sample size to model the influence of sex on survival. 
TABLE 3. Summary statistics of the candidate models examining the impact of urbanization on avian survival within the greater Washington, D.C., area; models are ranked by $\mathrm{AIC}_{\mathrm{c}}$ and $\log$ likelihood values are given.

\begin{tabular}{|c|c|c|c|c|c|c|c|}
\hline \multirow[b]{2}{*}{ Species code } & \multicolumn{2}{|c|}{ Model number } & \multirow[b]{2}{*}{$k$} & \multirow[b]{2}{*}{$\mathrm{AIC}_{\mathrm{c}}$} & \multirow[b]{2}{*}{$\Delta \mathrm{AIC}_{\mathrm{c}}$} & \multirow[b]{2}{*}{$w$} & \multirow[b]{2}{*}{$-2 \operatorname{LogLik}$} \\
\hline & $\Phi$ & $p$ & & & & & \\
\hline \multirow[t]{5}{*}{ AMRO } & 1 & 1 & 11 & 3184.48 & 0 & 0.721 & 3161.91 \\
\hline & 2 & 1 & 12 & 3186.58 & 2.10 & 0.252 & 3161.91 \\
\hline & 3 & 1 & 10 & 3191.79 & 7.30 & 0.018 & 3171.32 \\
\hline & 4 & 1 & 11 & 3193.83 & 9.34 & 0.006 & 3171.26 \\
\hline & 5 & 1 & 9 & 3198.41 & 13.92 & 0 & 3180.02 \\
\hline \multirow[t]{5}{*}{$\mathrm{CACH}$} & 5 & 1 & 9 & 16215.66 & 0 & 0.479 & 16197.33 \\
\hline & 3 & 1 & 10 & 16217.73 & 2.07 & 0.169 & 16197.32 \\
\hline & 4 & 1 & 11 & 16217.75 & 2.08 & 0.168 & 16195.25 \\
\hline & 2 & 1 & 12 & 16218.81 & 3.15 & 0.099 & 16194.22 \\
\hline & 1 & 1 & 11 & 16219.16 & 3.49 & 0.083 & 16196.66 \\
\hline \multirow[t]{5}{*}{ CARW } & 5 & 2 & 8 & 17657.64 & 0 & 0.498 & 17641.40 \\
\hline & 3 & 2 & 9 & 17659.54 & 1.90 & 0.192 & 17641.24 \\
\hline & 4 & 2 & 10 & 17660.44 & 2.80 & 0.122 & 17640.08 \\
\hline & 1 & 2 & 10 & 17660.83 & 3.18 & 0.101 & 17640.46 \\
\hline & 2 & 2 & 11 & 17661.17 & 3.52 & 0.085 & 17638.73 \\
\hline \multirow[t]{5}{*}{ GRCA } & 2 & 1 & 12 & 9814.62 & 0 & 0.442 & 9790.37 \\
\hline & 4 & 1 & 11 & 9815.99 & 1.36 & 0.223 & 9793.77 \\
\hline & 1 & 1 & 11 & 9816.52 & 1.90 & 0.170 & 9794.31 \\
\hline & 3 & 1 & 10 & 9816.69 & 2.06 & 0.157 & 9796.51 \\
\hline & 5 & 1 & 9 & 9823.14 & 8.51 & 0.006 & 9804.99 \\
\hline \multirow[t]{3}{*}{ HOWR } & 6 & 1 & 6 & 6181.53 & 0 & 0.446 & 6169.42 \\
\hline & 7 & 1 & 8 & 6181.85 & 0.31 & 0.381 & 6165.65 \\
\hline & 8 & 1 & 7 & 6183.44 & 1.90 & 0.172 & 6169.23 \\
\hline \multirow[t]{5}{*}{ NOCA } & 3 & 1 & 10 & 41351.09 & 0 & 0.440 & 41330.94 \\
\hline & 1 & 1 & 11 & 41352.19 & 1.09 & 0.254 & 41330.01 \\
\hline & 4 & 1 & 11 & 41353.13 & 2.03 & 0.159 & 41330.94 \\
\hline & 2 & 1 & 12 & 41354.20 & 3.10 & 0.093 & 41329.98 \\
\hline & 5 & 1 & 9 & 41355.34 & 4.24 & 0.052 & 41337.21 \\
\hline \multirow[t]{3}{*}{ SOSP } & 7 & 1 & 8 & 19245.18 & 0 & 0.870 & 19228.98 \\
\hline & 8 & 1 & 7 & 19249.14 & 3.96 & 0.120 & 19234.99 \\
\hline & 6 & 1 & 6 & 19254.31 & 9.13 & 0.009 & 19242.20 \\
\hline
\end{tabular}

Notes: Models for $\Phi$ are (1) sex $+\mathrm{BCI}+\mathrm{tsm}+\operatorname{sex} \times \mathrm{BCI}+\operatorname{sex} \times \operatorname{tsm}+\mathrm{IMP}+\mathrm{IMP}^{2}$; (2) sex + $\mathrm{BCI}+\mathrm{tsm}+\operatorname{sex} \times \mathrm{BCI}+\operatorname{sex} \times \mathrm{tsm}+\mathrm{IMP}+\mathrm{IMP}^{2}+\mathrm{IMP} \times \operatorname{sex} ;(3) \operatorname{sex}+\mathrm{BCI}+\mathrm{tsm}+\operatorname{sex} \times \mathrm{BCI}+$ sex $\times$ tsm + IMP; (4) sex + BCI + tsm + sex $\times$ BCI + sex $\times$ tsm + IMP + IMP $\times$ sex; (5) ex + BCI + $\mathrm{tsm}+(8) \mathrm{sex} \times \mathrm{BCI}+\mathrm{sex} \times \mathrm{tsm} ;(6) \mathrm{BCI}+\mathrm{tsm} ;(7) \mathrm{BCI}+\mathrm{tsm}+\mathrm{IMP}+\mathrm{IMP}^{2} ;(8) \mathrm{BCI}+\mathrm{tsm}+\mathrm{IMP}$. Models for $p$ are (1) sex + part; (2) sex.

species were reencountered at sites with greater than $50 \%$ impervious surface and $\beta$ estimates contained considerable uncertainty (Table 4; see Appendix A: Fig. A2). There was no evidence that impervious surface was predictive of Carolina Chickadee survival.

\section{DisCUSSION}

Understanding the demographic consequences of anthropogenic habitat change is essential as natural habitats are being rapidly converted to human dominated landscapes. Although urban land cover in the United States increased by 34\% during the last two decades of the 20th century, it is expected to increase by an additional $79 \%$ between 2000 and 2025 (Alig et al. 2004). Despite the increasing pace of urbanization, few studies have addressed survivorship of adult birds in urban environments (Chace and Walsh 2006), and none to our knowledge have yet explored survival along the rural-to-urban gradient from within urban or suburban matrices (but see Stracey and Robinson 2012). Here, we utilized a unique study designed to determine the effects of urbanization on the annual avian survival and to test hypotheses about which processes (e.g., top-down vs. bottom-up) regulate bird populations in human-dominated landscapes. We evaluated the annual survival of seven bird species common to suburban and urban matrices in a large-scale study of avian demography. By using the Smithsonian Neighborhood Nestwatch program, which utilizes citizen scientists throughout the greater Washington, D.C., metropolitan area, we were able to identify variation in survivorship along the ruralto-urban gradient, with higher apparent survival in suburban and urban environments for four of our seven species than at the rural end of the gradient. Cumulatively, our results suggest that the effect of urbanization influences avian vital rates, but that the regulatory mechanisms may be species specific.

Previous studies estimating adult survivorship of birds in human dominated systems have reported mixed results, most often showing little or no influence of urban land cover. Rodewald and Shustack $(2008 a, b)$, for example, found no difference between survivorship of Northern Cardinals occupying forests embedded within an urban matrix vs. those occupying forests 


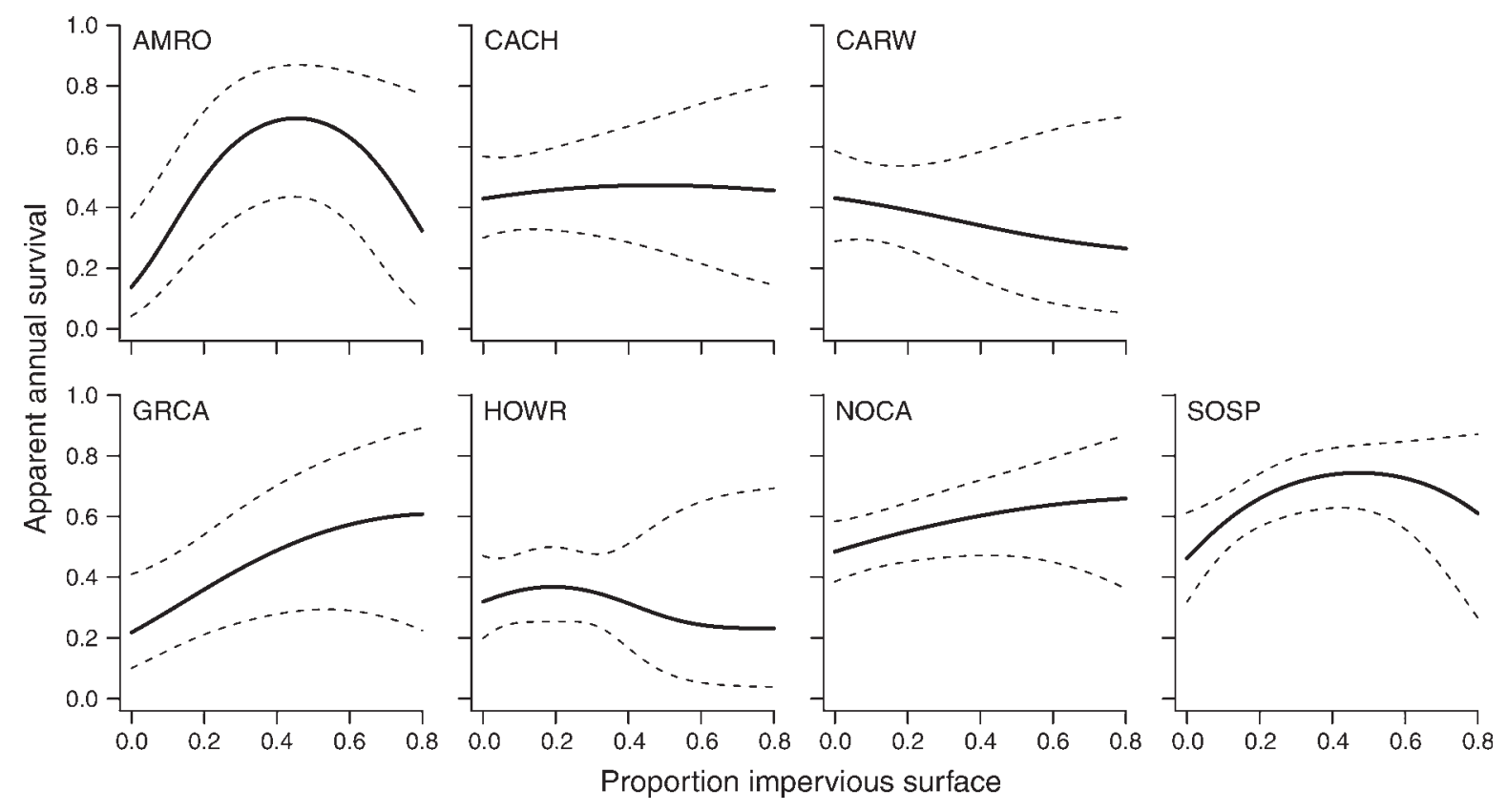

FIG. 3. Model-averaged estimates of American Robin, Carolina Chickadee, Carolina Wren, Gray Catbird, House Wren, Northern Cardinal, and Song Sparrow annual survival probabilities across the rural-to-urban gradient in greater Washington, D.C., USA.

embedded within a rural matrix. In contrast, our results provide supportive evidence for differential survival rates along the rural-to-urban gradient in six of our seven study species. The disparity between our results and those of other urban demographic studies may result from differences in sampling design, as we sampled extensively within the matrix as opposed to embedded forest parks. This suggests that the demographic effects of urbanization on matrix-dwelling species may be best observed from the urban-suburban matrix where these species exhibit peak abundances (B. S. Evans, R. Reitsma, and P. P. Marra, unpublished data).

\section{Top-down and bottom-up controls on avian population processes}

Observed patterns of survival across the rural-tourban gradient may offer clues as to mechanisms that underlie the demographic response. Urban environments are hypothesized to influence avian survival via increased rates of disease transmission, novel threats (e.g., collisions with man-made objects; Chace and Walsh 2006), and locally high densities of predators such as domestic cats (Sorace 2002; but see Shochat et al. 2010). Therefore, if avian survival is determined by top-down controls, we would expect that survivorship would decline with increasing urban land cover. Conversely, if resource availability determines survival in urban landscapes, it is expected that survivorship would be enhanced in these environments for many species due to anthropogenic resources (e.g., supplemental feeding), high densities of some invertebrates (especially for ground-foraging birds; see Szlavecz et al. 2006), and abundant fruit resources associated with ornamental and nonnative plants (McIntyre 2000, Reichard et al. 2001, Craves 2009; but see Tallamy 2004, Burghardt et al. 2009). The extent to which bottom-up effects regulate avian populations is likely to depend on the degree of urbanization, the type and abundance of available resources, and the life histories of the affected bird species.

Higher apparent survivorship for four of our focal species (American Robin, Gray Catbird, Northern Cardinal, and Song Sparrow) fits the pattern the expected of bottom-up controls on survival with increasing urbanization. These species are often considered habitat generalists (Poole 2013) and may therefore more readily adapt to challenges associated with urban landscapes (McKinney and Lockwood 1999). Additionally, a considerable proportion of the diets of these

TABLE 4. Model-averaged $\beta$ estimates for the influence of the proportional cover of impervious surface on annual survival probability.

\begin{tabular}{lrrrrr}
\hline & \multicolumn{2}{c}{ Impervious surface } & & \multicolumn{2}{c}{ Impervious surface } \\
\cline { 2 - 3 } \cline { 5 - 6 } Species code & $\bar{\beta}$ & $\overline{\mathrm{SE}}$ & & $\bar{\beta}$ & $\overline{\mathrm{SE}}$ \\
\hline AMRO & 11.78 & 3.04 & & -13.31 & 4.58 \\
CACH & 0.54 & 1.50 & & -3.88 & 5.31 \\
CARW & -0.39 & 1.53 & & -4.31 & 7.05 \\
GRCA & 2.50 & 0.97 & & -3.21 & 2.20 \\
HOWR & 4.26 & 2.82 & & -16.42 & 10.51 \\
NOCA & 1.57 & 0.74 & & -2.01 & 2.06 \\
SOSP & 5.21 & 1.65 & & -6.38 & 2.59 \\
\hline
\end{tabular}


species consist of fruit and invertebrate resources (Poole 2013), many of which are more abundant in urbansuburban environments (Raupp et al. 2010). Availability of winter fruit resources on nonnative and ornamental plants may provide relaxation from starvation pressures during winter months when survival of the resident species is dependent on a consistent food supply (Shochat et al. 2010). Because our support for the bottom-up control hypothesis is correlational, future studies that assess the distribution of resource availability are necessary.

Carolina Chickadee, Carolina Wren, and House Wren each exhibited their highest rates of survival at the rural portions of the gradient, with Carolina Chickadee showing no response to urbanization. The peak apparent survival of these species, however, was similar to the lowest annual survival of Northern Cardinal and Song Sparrow, suggesting low relative survival rates for these species across our study area. All of these cavity-nesting species exhibit very low abundances at the urban end of the gradient (B. S. Evans, R. Reitsma, and P. P. Marra, unpublished data). A lack of these individuals within the suburban and urban portions of the matrix may reflect a reduction in nesting resources due to a loss of adequate cavity trees or interspecific competition for nest cavities with matrix-dwelling species such as the European Starling Sturnus vulgarus and House Sparrow Passer domesticus (Newton 1994, Blewett and Marzluff 2005). Alternatively, observed patterns of survivorship and abundance for these species may be driven by declines in the size of suitable forest patches, the quality of the surrounding matrix along the rural-to-urban gradient, and/or behavioral avoidance of open urban habitats (Robbins et al. 1989, Medley et al. 1995).

\section{Potential influence of urbanization on avian fitness}

The influence of urbanization on adult survival may significantly alter avian fitness in human-dominated systems. Although the response of Northern Cardinal to urbanization was somewhat moderate, strong positive effects of urbanization on annual survival estimates of American Robin, Gray Catbird, and Song Sparrow suggest that habitat modification associated with urban land cover may positively influence population persistence for these species. If adult survivorship plays a dominant role in population persistence, our results predict differential population trajectories for Gray Catbird, Northern Cardinal, American Robin, and Song Sparrow relative to Carolina Wren, House Wren, and Carolina Chickadee in urban areas. Although the inference of this study is limited to the greater Washington, D.C., area and species common to this region, the $\mathrm{NN}$ model is currently being adopted in several other large metropolitan areas to provide a broader understanding of how urbanization shapes avian population demography (P. P. Marra, unpublished data).
Taken in concert with the finding that our study species exhibit greater nest success at higher levels of urbanization within the Washington, D.C., metropolitan area (Ryder et al. 2010), our results suggest that the suburban-urban matrix may be a source for American Robin, Gray Catbird, Northern Cardinal, and Song Sparrow in this region. Populations of these species exhibited their lowest rates of adult survivorship and nest success within the rural habitats of our study area, suggesting that undeveloped portions of this landscape may actually constitute a demographic sink for these species (Pulliam 1988). Although post-fledging survival in urban and suburban habitat contexts remains unknown (but see Balogh et al. 2011), the vital rate data provided here is a crucial starting point for understanding source-sink dynamics of bird populations along the urbanization gradient.

\section{Conclusion}

The costs and benefits of urbanization may differentially affect avian vital rates; therefore our understanding of the demographic consequences and sensitivity of populations to extinction in urban environments is of paramount importance. Our findings that the adult survival of several of our focal species was higher in urban relative to rural environments, in conjunction with previous findings of higher rates of nest success (Ryder et al. 2010), suggest that the effects of urbanization on these life history stages may facilitate the expansion of populations of some species of urbanadapted birds. It is important to highlight that this study focused on a suite of species prevalent in the urbansuburban matrix. Our work cannot, therefore, assess the impact of urbanization on urban-avoiding species, which probably have been disproportionately affected by anthropogenic habitat modification. Moreover, while the results of this study document substantial variation in apparent adult survival, our work cannot address how the mosaic of habitats within core urban and suburban environments shapes spatial and temporal population dynamics. Here we present correlative evidence of bottom-up regulation for a suite a species, yet further study is necessary to directly assess how the distribution of risks (such as building collisions and free-roaming cats) and resources (such as fruit and arthropods) vary along the rural-to-urban gradient. Ultimately, fully understanding how urbanization shapes ecological and evolutionary processes, and mitigating its effects, will require comparative studies that jointly document the mechanisms and the life history traits and demography of urban adapted and urban avoiding species.

\section{ACKNOWLEDGMENTS}

The Mills Corporation, Wallace Genetic Foundation, Susan and Frank Mars, Youth Access Grants, and the National Science Foundation (ESI-0540185) provided financial support for this study. We are grateful for the many talented field assistants for their contributions over the course of this project, as well as S. Cole, N. Diggs, A.M. Kilpatrick, and K. Sullivan 
for their invaluable training and support. Thanks to J. Sauer and two anonymous reviewers for substantive feedback that greatly improved the manuscript. Finally, we thank all of the Neighborhood Nestwatch participants for their kindness and commitment to this project.

\section{Literature Cited}

Akaike, H. 1973. Information theory and an extension of the maximum likelihood principle. Pages 267-281 in F. Csaki, editor. Second International Symposium on Information Theory. Akamemiai Kiado, Budapest, Hungary.

Alig, R. J., J. D. Kline, and M. Lichtenstein. 2004. Urbanization on the US landscape: Looking ahead in the 21 st century. Landscape and Urban Planning 69:219-234.

Amrhein, V., B. Scaar, M. Baumann, N. Minery, J. P. Binnert, and F. Korner-Nievergelt. 2012. Estimating adult sex ratios from bird mist netting data. Methods in Ecology and Evolution 3:713-720.

Atchison, K. A., and A. D. Rodewald. 2006. The value of urban forests to wintering birds. Natural Areas Journal 26: 280-288.

Ausprey, I. J., and A. D. Rodewald. 2011. Postfledging survivorship and habitat selection across a rural-to-urban landscape gradient. Auk 128:293-302.

Balogh, A. L., T. B. Ryder, and P. P. Marra. 2011. Population demography of Gray Catbirds in the suburban matrix: sources, sinks and domestic cats. Journal of Ornithology 152: 717-726.

Blair, R. B. 1996. Land use and avian species diversity along an urban gradient. Ecological Applications 6:506-519.

Blewett, C. M., and J. M. Marzluff. 2005. Effects of urban sprawl on snags and the abundance and productivity of cavity-nesting birds. Condor 107:678-693.

Breiman, L. 1996. Heuristics of instability and stabilization in model selection. Annals of Statistics 24:2350-2383.

Burghardt, K. T., D. W. Tallamy, and W. Gregory Shriver. 2009. Impact of native plants on bird and butterfly diversity in suburban landscapes. Conservation Biology 23:219-224.

Burnham, K. P., and D. R. Anderson. 2002. Model selection and multimodel inference: a practical information-theoretic approach. Second edition. Springer-Verlag, New York, New York, USA.

Chace, J. F., and J. J. Walsh. 2006. Urban effects on native avifauna: a review. Landscape and Urban Planning 74:4669.

Chamberlain, D. E., A. R. Cannon, M. P. Toms, D. I. Leech, B. J. Hatchwell, and K. J. Gaston. 2009. Avian productivity in urban landscapes: a review and meta-analysis. Ibis 151:118.

Cooper, C. B., J. Dickinson, T. Phillips, and R. Bonney. 2007. Citizen science as a tool for conservation in residential ecosystems. Ecology and Society 12(2):11.

Craves, J. A. 2009. A fifteen-year study of fall stopover patterns of Catharus thrushes at an inland, urban site. Wilson Journal of Ornithology 121:112-118.

Crooks, K. R., and M. E. Soulé. 1999. Mesopredator release and avifaunal extinctions in a fragmented system. Nature 400:563-566.

Danner, R. M., R. Greenberg, J. Danner, L. T. Kirkpatrick, and J. R. Walters. 2013. Experimental support for food limitation of a short-distance migratory bird wintering in the temperate zone. Ecology 94:2803-2816.

Doherty, P. F., and T. C. Grubb. 2002. Survivorship of permanent-resident birds in a fragmented forested landscape. Ecology 83:844-857.

Donald, P. F. 2007. Adult sex ratios in wild bird populations. Ibis 149:671-692.

Fry, J., G. Xian, S. Jin, J. Dewitz, C. Homer, L. Yang, C. Barnes, N. Herold, and J. Wickham. 2011. Percent Developed Imperviousness. National Land Cover Database 2006.
Multi-Resolution Land Characteristics Consortium (MRLC). http://www.mrlc.gov/nlcd06_data.php

Gates, J. E., and L. W. Gysel. 1978. Avian nest dispersion and fledging success in field-forest ecotones. Ecology 59:871-883.

Hijmans, Robert J. 2014. raster: Geographic data analysis and modeling. $\mathrm{R}$ package version 2.2-31. http://cran.r-project. org/package $=$ raster

Horak, P., and J. D. Lebreton. 1998. Survival of adult Great Tits Parus major in relation to sex and habitat; a comparison of urban and rural populations. Ibis 140:205-209.

Johnson, M. D., T. W. Sherry, R. T. Holmes, and P. P. Marra. 2006. Assessing habitat quality for a migratory songbird wintering in natural and agricultural habitats. Conservation Biology 20:1433-1444.

Kilpatrick, A. M. 2011. Globalization, land use, and the invasion of West Nile Virus. Science 334:323-327.

Laake, J. L. 2013. RMark: an R interface for analysis of capture-recapture data with MARK. National Marine Fisheries Service, National Marine Mammal Laboratory, Alaska Fisheries Science Center (AFSC) Processed Rep 2013-01, Seattle, Washington, USA. http://www.afsc.noaa. gov/publications/procrpt/pr2013-01.pdf

Leston, L. F., and A. D. Rodewald. 2006. Are urban forests ecological traps for understory birds? An examination using Northern Cardinals. Biological Conservation 131:566-574.

Liker, A., Z. Papp, V. Bókony, and A. Z. Lendvai. 2008. Lean birds in the city: body size and condition of house sparrows along the urbanization gradient. Journal of Animal Ecology 77:789-795.

Loss, S. R., T. Will, and P. P. Marra. 2013. The impact of free-ranging domestic cats on wildlife of the United States. Nature Communications 4:1396.

Loss, S. R., T. Will, and P. P. Marra. 2014a. Estimates of annual bird mortality from vehicle collisions on roads in the United States. Journal of Wildlife Management 78:763-771.

Loss, S. R., T. Will, and P. P. Marra. 2014b. Bird-building collisions in the United States: estimates of annual mortality and species vulnerability. Condor: Ornithological Applications 116:8-23.

Marzluff, J. M., R. Bowman, and R. E. Donnelly. 2001. Avian ecology and conservation in an urbanizing world. Kluwer Academic Publishers, Norwell, Massachusetts, USA.

McCusker, C. E., M. P. Ward, and J. D. Brawn. 2010. Seasonal responses of avian communities to invasive bush honeysuckles (Lonicera spp.). Biological Invasions 12:2459-2470.

McIntyre, N. E. 2000. Ecology of urban arthropods: A review and a call to action. Annals of the Entomological Society of America 93:825-835.

McKinney, M. L. 2002. Urbanization, biodiversity, and conservation. BioScience 52:883-890.

McKinney, M. L., and J. L. Lockwood. 1999. Biotic homogenization: a few winners replacing many losers in the next mass extinction. Trends in Ecology and Evolution 14: $450-453$.

Medley, K. E., M. J. McDonnell, and S. T. Pickett. 1995. Forest-landscape structure along an urban-to-rural gradient. Professional Geographer 47:159-168.

Murphy, M. T. 1996. Survivorship, breeding dispersal and mate fidelity in Eastern Kingbirds. Condor 98:82-92.

Newton, I. 1994. The role of nest sites in limiting the numbers of hole-nesting birds: a review. Biological Conservation 70: 265-276.

Peig, J., and A. J. Green. 2009. New perspectives for estimating body condition from mass/length data: the scaled mass index as an alternative method. Oikos 118:1883-1891.

Poole, A., editor. 2013. The Birds of North America Online. Cornell Laboratory of Ornithology, Ithaca, New York, USA. http://bna.birds.cornell.edu/BNA/

Pradel, R. 1996. Utilization of capture-mark-recapture for the study of recruitment and population growth rate. Biometrics 52:703-709. 
Pulliam, H. R. 1988. Sources, sinks, and population regulation. American Naturalist 132:652-661.

Pyle, P., S. N. G. Howell, R. P. Yunick, and D. F. DeSante 1997. Identification guide to North American Passerines. First edition, Slate Creek Press, Bolinas, California, USA

$\mathrm{R}$ Core Team. 2014. R: a language and environment for statistical computing. R Foundation for Statistical Computing, Vienna, Austria. http://www.r-project.org/

Raupp, M. J., P. M. Shrewsbury, and D. A. Herms. 2010 Ecology of herbivorous arthropods in urban landscapes. Annual Review of Entomology 55:19-38.

Reichard, S. H., L. Chalker-Scott, and S. Buchanan. 2001. Interactions among non-native plants and birds. Pages 179-223 in J. M. Marzluff, R. Bowman, and R. Donnelly, editors. Avian ecology and conservation in an urbanizing world. Springer, New York, New York, USA.

Robb, G. N., R. A. McDonald, D. E. Chamberlain, and S. Bearhop. 2008. Food for thought: supplementary feeding as a driver of ecological change in avian populations. Frontiers in Ecology and the Environment 6:476-484.

Robbins, C., D. Dawson, and B. Dowell. 1989. Habitat area requirements of breeding forest birds of the Middle Atlantic states. Wildlife Monographs 103:1-34.

Rodewald, A. D., and D. P. Shustack. 2008a. Urban flight: understanding individual and population-level responses of Nearctic-Neotropical migratory birds to urbanization. Journal of Animal Ecology 77:83-91.

Rodewald, A. D., and D. P. Shustack. 2008b. Consumer resource matching in urbanizing landscapes: Are synanthropic species over-matching? Ecology 89:515-521.

Roux, K. E., and P. P. Marra. 2007. The presence and impact of environmental lead in passerine birds along an urban to rural land use gradient. Archives of Environmental Contamination and Toxicology 53:261-268.
Ryder, T. B., R. Reitsma, B. Evans, and P. P. Marra. 2010. Quantifying avian nest success along an urbanization gradient using citizen and scientist generated data. Ecological Applications 20:419-426.

Shochat, E. 2004. Credit or debit? Resource input changes population dynamics of city slicker birds. Oikos 106:622-626.

Shochat, E., S. Lerman, and E. Fernández-Juricic. 2010. Birds in urban ecosystems: Population dynamics, community structure, biodiversity, and conservation. Urban Ecosystem Ecology 75-86.

Shochat, E., P. S. Warren, S. H. Faeth, N. E. McIntryre, and D. Hope. 2006. From patterns to emerging processes in mechanistic urban ecology. Trends in Ecology and Evolution $21: 2-7$.

Sorace, A. 2002. High density of bird and pest species in urban habitats and the role of predator abundance. Ornis Fennica 79:60-71.

Stracey, C. M., and S. K. Robinson. 2012. Are urban habitats ecological traps for a native songbird? Season-long productivity, apparent survival, and site fidelity in urban and rural habitats. Journal of Avian Biology 43:50-60.

Szlavecz, K., S. A. Placella, R. V. Pouyat, P. M. Groffman, C. Csuzdi, and I. Yesilonis. 2006. Invasive earthworm species and nitrogen cycling in remnant forest patches. Applied Soil Ecology 32:54-62.

Tallamy, D. W. 2004. Do alien plants reduce insect biomass? Conservation Biology 18:1689-1692.

White, G. C., and K. P. Burnham. 1999. Program MARK: survival estimation from populations of marked animals. Bird Study 46(Supplement):120-138.

Whittaker, K. A., and J. M. Marzluff. 2009. Species-specific survival and relative habitat use in an urban landscape during the postfledging period. Auk 126:288-299.

\section{Supplemental Material}

\section{Ecological Archives}

Appendices A and B are available online: http://dx.doi.org/10.1890/14-0171.1.sm 